\title{
Notes on Puerto Rican Drosophilidae, Including Descriptions of Two New Species of Drosophila ${ }^{1}$
}

\author{
J. Ives Townsend ${ }^{2}$ and Marshall R. Wheeler ${ }^{3}$
}

\section{INTRODUCTION}

Taxonomic interest in the Drosophilidae is great, primarily because of the value of the family for studies in genetics and evolution; thus it has become one of the very best known Dipteran families. Although no intensive effort has yet been made to obtain a large representative collection of Drosophilidae in Puerto Rico, Sturtevant (4) ${ }^{4}$ has published a list of Puerto Rican species that he examined in several collections, and Wolcott (8) has published a list of species reported elsewhere in the literature.

\section{REVISIONS WITHIN THE FAMILY AND COLLECTIONS IN PUERTO RICO}

Several revisions have been made within the family (see, for example, $3,7)$ since these Puerto Rican lists were published. Sturtevant included Drosophila opaca Williston and $D$. caribbea Sturtevant in his original list. However, he (5, p. 27) later transferred the former species to the genus Diathoneura. Duda (1, p. 223) pointed out that D. caribbea Sturtevant was a synonym of $D$. ananassae Doleschall. Sturtevant's list, with these changes to conform with current taxonomy, is indicated in column 1 of table 1. In column 2 of the same table a revision of Wolcott's list is indicated. On the authority given below the following names have been omitted from this list:

D. ampelophita Loew, according to Sturtevant (4, p. 105) a synonym of D. melanogaster Meigen .

D. fusca Coquillett, according to Sturtevant (4, p. 106) a possible synonym of $D$. lutzii Sturtevant

${ }^{1}$ Collecting in Puerto Rico in 1952-53 was by the senior author, supported in part by a grant from the Penrose Fund of the American Philosophical Society. It is a pleasure to thank George N. Wolcott of the Agricultural Experiment Station of the University of Puerto Rico, Río Piedras, and Honorico Ciordia, formerly of that Station, for their generosity in lending their laboratory facilities and for their many other courtesies during the collecting, and to express appreciation to Frank H. Wadsworth : of the U. S. Forest Service, Caribbean Division, Río Piedras, for his kindness in providing a guide and transportation for collecting in the Caribbean National Forest.

${ }^{2}$ Assistant Professor of Zoology, University of Tennessee, Knoxville, Tenn. This paper is Contribution No. 94 from the Department of Zoology and Entomology, University of Tennessee.

${ }^{3}$ Assistant Professor of Zoology, University of Texas, Austin, Tex.

${ }^{4}$ Numbers in parentheses refer to Literature Cited, p. 64. 
TABLI 1.-The Drosophilidae of Puerto Rico: Columns 1 and 2 are based on the publications of the indicated authors; columns 8,4 , and 5 report species collected in 1952 and 1953 in the localities indicated; in columns 9-5 the actual number of specimens collected is given when less than 6

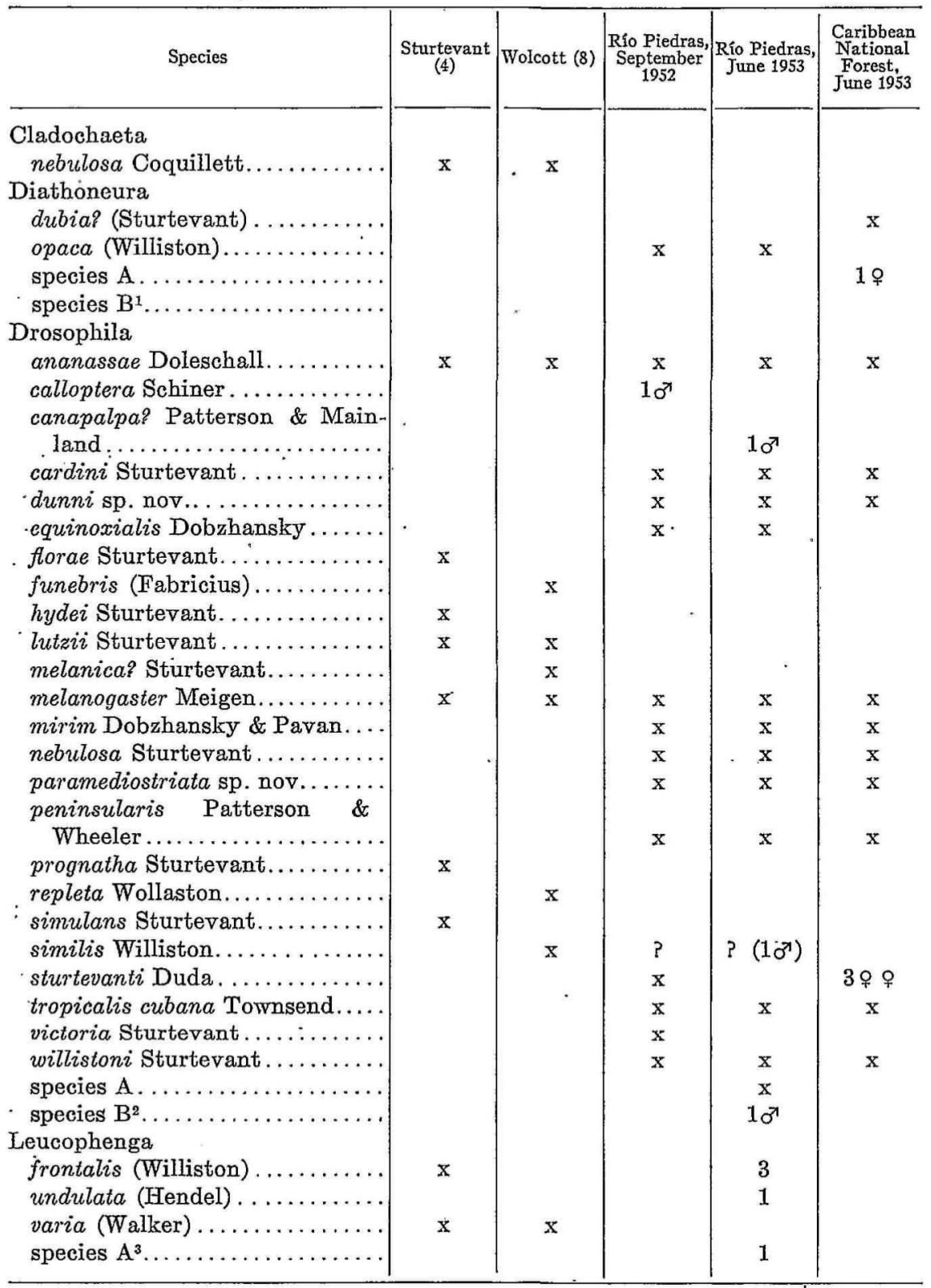


TABLI 1.-Continued .

\begin{tabular}{|c|c|c|c|c|c|}
\hline Species & $\underset{(4)}{\text { Sturtevant }}$ & Wolcott (8) & $\begin{array}{c}\text { Río Piedras, } \\
\text { September } \\
1952\end{array}$ & $\mid$\begin{tabular}{|l} 
Río Piedras, \\
June 1953
\end{tabular} & $\begin{array}{l}\text { Carribean } \\
\text { National } \\
\text { Forest, } \\
\text { June 1953 }\end{array}$ \\
\hline $\begin{array}{l}\text { Microdrosophila } \\
\text { quadrata (Sturtevant) } \ldots \ldots \ldots \ldots \\
\text { Neotanygastrella } \\
\quad \text { tricoloripes Duda } \ldots \ldots \ldots \ldots \ldots \\
\text { Scaptomyza } \\
\text { vittata (Coquillett) } \ldots \ldots \ldots \ldots \ldots\end{array}$ & ? & $\mathrm{x}$ & r & $x$ & $\begin{array}{l}x \\
x\end{array}$ \\
\hline
\end{tabular}

${ }_{1}^{1}$ Resembles somewhat Diathoneura metallica Sturtevant. A single female was taken in either Rio Piedras or the Caribbean National Forest, Puerto Rico, in June 1953.

${ }^{2}$ Probably belongs to the annulimana group.

${ }^{3}$ Has dark wing pattern similar to, but more intense than, that of Leucophenga maculosa, but has quite different abdominal pattern, much narrower front, and palpi that are not noticeably enlarged.

D. punctulatus Loew, according to Sturtevant (4, p. 106) a synonym of D. repleta Wollaston

Stenomicra augustata Coquillett, according to Malloch (2, p. 23-24) best placed in the Asteiidae or Anthomyzidae; Sturtevant (6) relegates it to the Anthomyzidae.

Recently, incidental to the collecting of Drosophila willistoni in Puerto Rico, a number of Drosophilidae not previously reported from this Island have been obtained. Collections were made on the grounds of the Agricultural Experiment Station of the University of Puerto Rico, Río Piedras, September 10-12, 1952, and June 9-12, 1953, and also in the Caribbean National Forest, June 10, 1953. Windfallen, fermenting fruits-principally Artocarpus communis and Annona reticulata in 1952, and A. communis and Mangifera indica in 1953-were the most effective bait. Yeasted banana pulp was used to supplement these fruits. The Drosophilidae taken in these collections are indicated in columns 3,4 , and 5 of table 1 . These include several previously undescribed species, of which two species of Drosophila, are described below.

Although ecological conditions in southern Florida and in Puerto Rico are rather different, they are still similar enough to make interesting a comparison of species of Drosophilidae known from these two regions. For this purpose all Drosophilidae that have been taken by collectors from the University of Texas laboratories or by the senior author in Florida south 
of the 29th parallel are listed in the following tabulation:

The Drosophitidae of peninsular Florida south of the 29th Parallel, based on collections made by collectors from the University of Texas and by the senior author:

Drosophila

acutilabella Stalker ${ }^{1}$

affinis Sturtevant

americana texana Patterson, Stone, \&

Griffen

ananassae Doleschall

busckii Coquillett

cardini Sturtevant

deflecta Malloch \& McAtee

duncani Sturtevant

guttifera Walker

hydei Sturtevant

immigrans Sturtevant

macrospina Stalker \& Spencer

melanica Sturtevant

melanissima Sturtevant

melanogaster Meigen

micromelanica Patterson

mirim Dobzhansky \& Pavan

mulleri Sturtevant

nebulosa Sturtevant

nigromelanica Patterson \& Wheeler

peninsularis Patterson \& Wheeler

putrida Sturtevant

repleta Wollaston.

robusta Sturtevant

simulans Sturtevant

transversa Fallen tripunctata Loew

virilis Sturtevant

willistoni Sturtevant

Chymomyza

procnemis (Williston)

Diathoneura

opaca (Williston)

Gitona

americana Patterson

bivisualis Patterson

Leucophenga

maculosa (Coquillett)

varia (Walker)

Microdrosophila

quadrata (Sturtevant)

Mycodrosophila

dimidiata (Loew)

Scaptomyza

adusta (Loew)

vittata (Coquillett)

${ }^{1}$ Kindly identified by Harrison D. Stalker.

The 26 species of Drosophila and 12 species of non-Drosophila Drosophilidae now reported from Puerto Rico compare favorably with the 29. and the 10 species in the respective classes reported from southern Florida. Nevertheless the Puerto Rican list is by no means exhaustive. One indication of this is the fact that at least two cosmopolitan species, Drosophila busckii Coquillett and $D$. immigrans Sturtevant, very likely present in the Island are yet to be reported from there. It appears that further collecting in . Puerto Rico will be rewarding to the taxonomist and illuminating to the evolutionist who, since Darwin, has increasingly appreciated the importance of insular species. 


\section{DESCRIPTIONS OF SPECIES}

Types of the following new species have been deposited in the collections of the Department of Zoology of the University of Texas; some paratypes have been deposited in the collection of the Department of Zoology and Entomology of the University of Tennessee.

\section{Drosophila dunni, SPECIES NOVA}

\section{External characters of imagines}

$\sigma^{7}$. Arista with about 8-10 branches, 9 being the usual number. Antennae tan, third joint somewhat darker. Front tan, dull and velvety except ocellar triangle and area of orbital bristles. Middle orbital about $1 / 3$ other 2 . Second oral bristle about as long as first. Carina broad and flat; face yellowish tan. Cheeks pale yellow, their greatest width about $1 / 5$ greatest diameter of eyes. Eyes bright red, clothed with short black pile. Acrostichals in 6 rows; no prescutellars. Anterior scutellars convergent. Mesonotum, scutellum, and pleurae shining brownish tan. Sterno-index about 0.5 . Legs yellow; fore tarsi with many short recurved hairs, their length about equal to the diameter of the tarsal segments. Apical bristles on first and second tibiae, preapicals on all 3.

Abdomen shining yellow, each segment with a medianly interrupted, narrow apical band which narrows and becomes fainter at the angle of the tergite; some individuals with bands very faint and scarcely discernible.

Wings clear. Costal index about 3.5 ; fourth-vein index about $1.9 ; 5 \mathrm{x}$ index about $1.8 ; 4 \mathrm{c}$ index about 0.8 . One prominent bristle at apex of first costal section. Third costal section with heavy bristles on basal $1 / 3$.

Length body $2.3 \mathrm{~mm}$. (in live specimen); wings $1.9 \mathrm{~mm}$.

ㅇ. Fore tarsi with few, or no, short recurved hairs. Length body 2.7 mm.; wings $2.3 \mathrm{~mm}$.

\section{Internal characters of imagines}

Testes with about 4 pale yellow outer coils and $31 / 2$ whitish inner coils or gyres.

Spermathecae medium brown in color and chitinized. Ventral receptacle with about 15 coils in long spiral.

Single anterior Malpighian tube, branched at distal end; 2 posterior tubes with distal ends opposed without formation of a continuous lumen.

\section{Other characteristics, relationship, and distribution}

EGGs. -4 filaments, tapering toward distal ends. Egg length about 0.52 $\mathrm{mm}$. 
PUPARIA.-Amber. Each anterior spiracle with about 11 branches. Horn index about 5.0.

CHROMOSOMES.- Metaphase plate with a pair of short rods, a pair of long rods, and 2 pairs of U's.

RELATIONSHIP.-Belongs to the cardini group of the subgenus Drosophila. Distribution.-Puerto Rico: Río Piedras and Caribbean National Forest.

HOLOTYPE MALE.-Holotype and paratypes descendants of a single female collected at Río Piedras in September 1952.

N. b.: This species is named in honor of L. C. Dunn of Columbia University.

\section{Drosophita paramediostriata, SPECIES NOVA}

External characters of imagines

$\sigma^{7}$. Arista with about 10-12 branches. Antennae tan, third joint somewhat darker. Front tannish brown. Anterior orbital about $3 / 4$ posterior; middle orbital little larger than surrounding hairs. Second oral bristle about as long as first. Carina wider below, flat, not sulcate. Palpi pale yellow, with several prominent bristles. Face tannish yellow. Cheeks pale yellow, their greatest width about $1 / 4$ greatest diameter of eyes. Eyes red, with light-colored pile.

Acrostichals in 6 rows; no prescutellars. Anterior scutellars divergent. Mesonotum and scutellum tannish brown without markings; pleurae lighter. Sterno-index about 0.6. Legs pale yellowish tan. Apical bristles on first and second tibiae; preapicals on all 3. Front femora with an immigranslike row of short black spines.

Abdomen dark yellow, each segment with a broad apical brown band, each band usually extending to lateral margin except on basal segment; apical bands on tergites 1-3 thinner in middle; apical bands on tergites 4-6 each with median projection, sometimes reaching anterior margin on tergites 5 and 6 , but not on tergite 4 ; bands larger and darker in posterior segments.

Wings with posterior crossveins slightly clouded, remainder clear. Costal index about 3.8; fourth-vein index about 1.6; $5 \mathrm{x}$ index about 1.5 ; $4 \mathrm{c}$ index about 0.7. Apex of first costal section with two well-developed bristles. Third costal section with heavy bristles on basal $1 / 2$.

Length body $2.2 \mathrm{~mm}$. (in live specimen); wings $2.2 \mathrm{~mm}$.

ㅇ. Length body $2.7 \mathrm{~mm}$; wings $2.5 \mathrm{~mm}$.

\section{Internal characters of imagines .}

Testes pale yellow with about 3 outer and 3 inner coils or gyres. Ejaculatory sac with 2 long posterior diverticula. 
Spermathecae spherical, lightly chitinized. Ventral receptacle with about 26 irregular coils.

\section{Other characteristics, relationship, and distribution}

EGGS.-4 slender filaments; egg length about $0.44 \mathrm{~mm}$.

PUPARIA.-Reddish amber. Each spiracle with about 20 branches. Horn index about 3.0 .

CHRomosomes.-Metaphase plate with 5 pairs of rods and 1 pair of dots; 1 pair of rods about twice as long as others.

RELATIONSHiP.-Belongs to the tripunctata group of the subgenus Drosophila. It is very similar to $D$. mediostriata Duda, but that species has a median spot without a band on the sixth tergite; there are also some small differences in the male genitalia.

Distribution.-Collected in Puerto Rico: Río Piedras and Caribbean National Forest.

HоLOTXPE MALE.-Holotype and paratypes descendants of females collected at Rio Piedras in September 1953.

\section{SUMMARY}

When necessary allowances are made for conformity with current taxonomy of the Drosophilidae, it is seen that. 15 species, of which 11 are Drosophila and 4 non-Drosophila Drosophilidae, have previously been reported from Puerto Rico. Recent, but not extensive, collecting in this Island has resulted in capture of 27 species of Drosophilidae. Eight species of nonDrosophila Drosophilidae and 15 species of Drosophila in the recent collections have not previously been reported from Puerto Rico. Among these unreported forms are two new species of Drosophila that are described herein.

The number of species of Drosophilidae now reported from Puerto Rico compares favorably with that reported from peninsular Florida south of the 29 th parallel.

\section{RESUMEN}

Cuando se hacen las necesarias concesiones a la taxonomía corriente de las Drosophilidae, se ve que 15 especies, de las cuales 11 son Drosophila y 4 no Drosophila Drosophilidae, se han informado previamente de Puerto Rico. Recientemente, aunque no en forma extensiva, el esfuerzo hecho por colector este género de insectos en la Isla ha redundado en la captura de 27 especies de Drosophilidae. Ocho especies no Drosophila Drosophilidae y 15 especies Drosophila incluídas en las recientes colecciones no se babían informado previamente de Puerto Rico. Entre estas formas sin informar hay 2 nuevas especies de Drosophila las cuales se informan en este trabajo. 
El número de especies de Drosophilidae, hasta ahora informado de Puerto Rico, compara favorablemente con el de la peninsula de Florida, al sur del paralelo 29.

\section{LITERATURE CITED}

1. Duda, O., Die costaricanischen Drosophiliden (Dipteren) des Ungarischen National Museums zu Budapest; Ann. Mus. Nat: Hung. 22 149-229, 1925.

2. Malloch, J. R., The species of the genus Stenomicra Coquillett, Ann. Mag. Nat. Hist., Ser. 920 23-6, 1927.

3. Patterson, J. T., and Wheeler, M. R., Catalogue of deseribed species belonging to the genus Drosophila, with observations on their geographical distribution, Univ. Texas Publ. 4920, 207-33, 1949.

4. Sturtevant, A. H., The North American species of Drosophila, Carn. Inst. of Wash. Publ. 301, 1-150, 1921.

5. - The classification of the genus Drosophila, with descriptions of nine new species, Univ. Texas Publ. 4213, 6-51, 1942.

6. - The Nearctic species of Periscelidae (Diptera), and of certain Anthomyzidae that have been referred to the family, Proc. U. S. Nat. Mus. 103 (3332) 551-61, 1954.

7. Wheeler, M. R., The Drosophilidae of the nearctic region, exclusive of the genus Drosophila, Univ. Texas Publ. 5204, 162-218, 1952.

8. Wolcott, G. N., The insects of Puerto Rico: Diptera, J.Agr. Univ. P. R. 32 418-532, 1948. 